\title{
OPEN DATA IN HEALTH-GEOMATICS: MAPPING AND EVALUATING PUBLICLY ACCESSIBLE DEFIBRILLATORS
}

\author{
L. Gianquintieri ${ }^{1}$, E. G. Caiani ${ }^{1}$, P. Brambilla ${ }^{2}$, A. Pagliosa ${ }^{2}$, G. F. Villa ${ }^{2}$, M. A. Brovelli ${ }^{3}{ }^{*}$ \\ ${ }^{1}$ Politecnico di Milano, Electronics, Information and Bioengineering Dpt, Milan, Italy \\ ${ }^{2}$ Azienda Regionale Emergenza/Urgenza - AREU, Milan, Italy \\ ${ }^{3}$ Politecnico di Milano, Civil and Environmental Engineering Dpt, Milan, Italy - maria.brovelli@ polimi.it
}

Commission IV, WG IV/4

KEY WORDS: Public Access Defibrillation, PAD, Automated External Defibrillator, AED, Out-Of-Hospital Cardiac Arrest, OHCA, Catchment Areas Mapping, Health-Geomatics

\begin{abstract}
:
To address the study of the deployment of publicly accessible Automated External Defibrillators (AED), Geomatics allows computing their limited area of effectiveness (i.e. 'catchment area', CA), traditionally set as circular surfaces with a $100 \mathrm{~m}$-radius. Exploiting open geospatial data related to roads network, also 'realistic' CAs, based on the effective walking distance, can be computed. Aim of this study (performed on the territory of Lombardy, Italy, total surface 23 ' $863.65 \mathrm{~km}^{2}$, with open source software as QGIS, PostGIS, pgRouting) was to compare the two approaches, and to evaluate if the territory analysis could support case-bycase decision-making about the preferable mapping technique.

Setting a limit of 200m, realistic CAs were computed for 7702 known AEDs on the territory (at 28/02/2018). The mean area obtained resulted close to that of the traditional $100 \mathrm{~m}$-radius circular area $\left(33^{\prime} 665 \mathrm{~m}^{2}\right.$ against $\left.31^{\prime} 415 \mathrm{~m}^{2}\right)$, but the spatial coverage of 45043 OHCAs - Out-of-Hospital Cardiac Arrests (Lombardy, 1/1/2015 to 31/12/2018) is very different considering realistic or circular areas $(15.35 \%$ vs $9.43 \%)$. The distribution of the mapping error (realistic-CA - circular-CA) and the computation failures of realistic areas were studied and correlated with the characteristics of the surrounding territory considering attributes related to streets, buildings, and land-use, computing linear correlation coefficients and performing Mann-Whitney U-tests. Results suggest that realistic CAs are not always correctly computable and circular areas are preferable when AEDs are far from the streets in less urbanized and more uniform territories. An automatized decision-making about the best case-by-case mapping technique is therefore feasible with open data and open source software.
\end{abstract}

\section{INTRODUCTION}

\subsection{Out-of-Hospital Cardiac Arrest (OHCA) and Public Access Defibrillation (PAD)}

The 'Out-of-Hospital Cardiac Arrest' (OHCA) is defined by the American Heart Association (AHA) as the cessation of mechanical cardiac activity outside of a medical care setting (Roger, 2011). This is a highly life-threatening condition, with an overall survival rate lower than $10 \%$ (7.6\% in the USA in 2010 (Sasson, 2010)). In general, survival is strongly related with cardiopulmonary resuscitation, and with time of first defibrillation, as the survival rate decreases from a baseline of $67 \%$ by $7-10 \%$ for each minute elapsing from the moment of the arrest (Bonnet, 2015). In order to reduce time of first defibrillation, the leading strategy is Public Access Defibrillation (PAD), based on the deployment along cities' territory of publicly retrievable Automated External Defibrillators (Weisfeldt, 1995), enabling bystanders to defibrillate victims even before arrival of Emergency Medical Services (EMS).

Despite PAD programs are now diffused worldwide (Mauri 2016, Smith 2017), it is widely recognized that they are not working as intended (Deakin 2014, Renhao 2016). One of the main issues is the spatial accessibility of the devices: as the time limit for an effective defibrillation is 6 minutes (Zulli 2016),
AEDs cannot be effectively used if the lay rescuer cannot cover the distance (back and forth) between the victim and the location of the AED within this time limit. Therefore, a geographical analysis is required in order to assess the efficiency of AEDs positioning along the territory. Many studies were performed in the last years in order to evaluate AEDs spatial accessibility and to identify and propose better strategies for their deployment (Bonnet 2015, Chan 2017, Folke 2010, Lin 2016, Sun 2016, Tierney 2018).

\subsection{Problem statement}

All the studies about spatial accessibility of public AEDs are based on the definition of their 'catchment area', which is the portion of territory potentially covered by the presence of a device. However, there is currently no assessed indication on how to convert the defined time limit of 6 minutes into a spatial measurement for the corresponding areas. For example, guidelines from AHA only suggest considering a time limit of 3 minutes (which corresponds to 6 minutes back and forth) to plan the placement of the AEDs (American Heart Association, 2018). Traditionally, most of the studies computed the catchment areas according to guidelines from AHA (Aufderheide, 2006) as circular surfaces centred on the device with a radius of $100 \mathrm{~m}$, thus based on Euclidian distance (Chan 2017, Sun 2016, Tierney 2018). However, one study (Bonnet

\footnotetext{
* Corresponding author
} 
2015) proposed the computation of 'realistic' catchment areas, based on the topology of the streets and therefore on actual routable paths between the position of the device and the potential locations of arrests (therefore, based on a 'routing' distance). An example of these two different mapping techniques is reported in figure 1. Although this second approach could be intuitively preferred, since it better suits the real-world scenario, there is currently no quantitative assessment about the mapping differences generated by the two techniques in a real scenario. Moreover, whereas the circular areas can always be computed, realistic mapping implies more complex routing issues, and no study verifying the conditions necessary for an effective computation was ever performed.

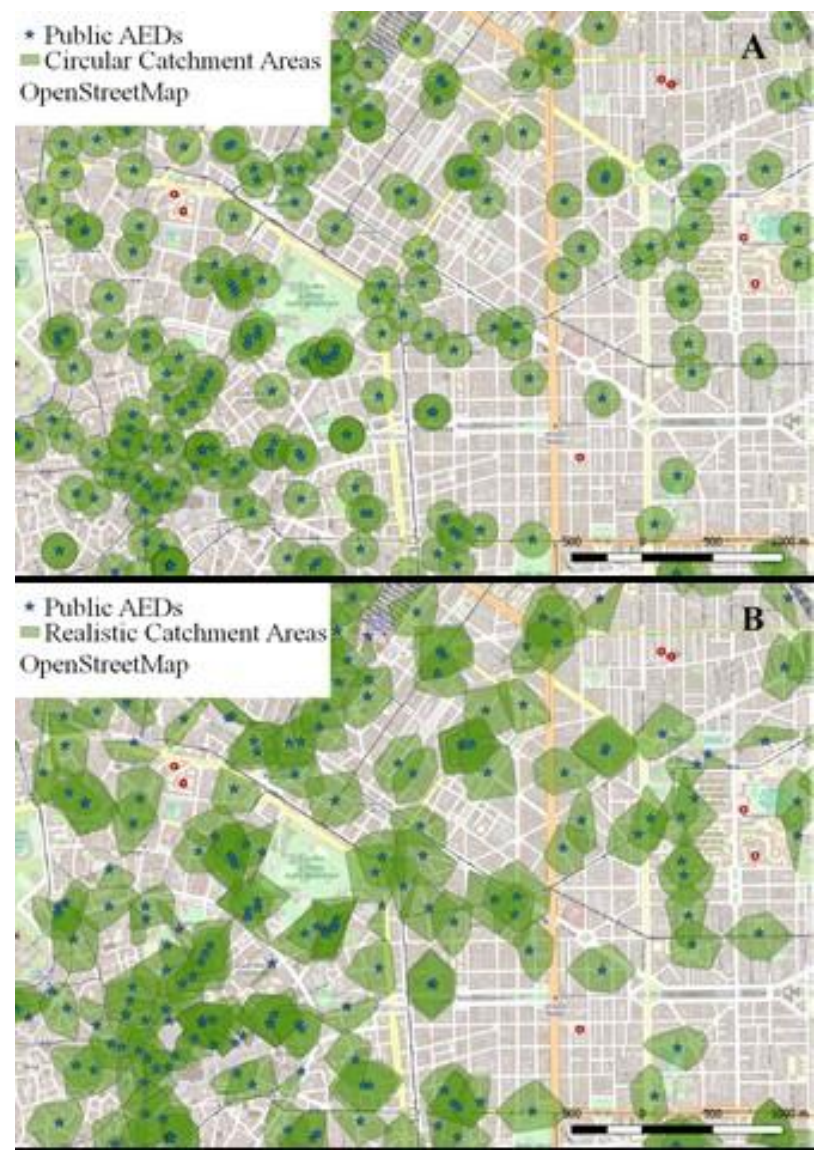

Figure 1. Mapping of catchment areas for AEDs in a portion of the city of Milan (Lombardy, Italy), with circular (panel A) and realistic (panel B) areas.

\subsection{Hypothesis and aim}

We hypothesized that, despite being realistic areas more representative of the real-world scenario, it is not always possible to compute catchment areas with the realistic approach, and, therefore, circular areas could in some cases be preferable, depending on the topology of the considered territory. To verify this hypothesis, we used an open source GIS, specifically QGIS, that is the tool identified by literature as the most suitable in performing studies about PAD programs (Chan 2013, Folke 2009, Ringh 2018).

Accordingly, our aim was to implement the mapping of catchment areas with the realistic approach and to compare them with the circular ones. In addition, we wanted to identify geographical attributes in the area surrounding AEDs that could provide case-by-case reliable information about the choice of the best mapping technique, in order to assess the feasibility of an automatized decision-making between the two techniques when mapping catchment areas, and to preventively identify specific devices for whom it is impossible to compute the realistic area, due to surroundings' characteristics.

In order to enhance the replicability of the study, we decided to exploit open data only, except a georeferenced database of OHCAs, which was provided by Azienda Regionale Emergenza/Urgenza (AREU, the EMS provider and responsible for 118 sanitary emergency calls in Lombardy) and cannot be made available as open data, being related to medical (and therefore sensible) information.

\section{MAIN BODY}

\subsection{Data sources and pre-processing}

As a case-study, we considered the territory of Lombardy region (Italy), whose area is $23^{\prime} 863.65 \mathrm{~km}^{2}$ and has a resident population of 10'055'148 people.

As previously stated, AREU provided the georeferenced database of all OHCAs occurred within 01/01/2015 and $31 / 12 / 2018$ in the region (for a total of 45043 events), and the georeferenced database of known publicly accessible AEDs on the regional territory at 28/02/2018 (for a total of 7702 devices), which is also available as open data.

The shapefiles related to roads and buildings were obtained through the OpenStreetMap portal, whereas information related to land-use was retrieved as open data from the Lombardy region geoportal. In particular, the DUSAF database was used, which is a shapefile representing a unique vector layer covering the whole territory, where single features are classified according to the use of the land (urbanized, transports, natural, agricultural etc.) with a 5-digits code (updated at 30/01/2017).

All these data sources were imported in QGIS as shapefiles representing vector layers, and converted into the World Geodetic System 84 (WGS84) - Universal Transverse Mercator (UTM) 32 North coordinates reference system. All links related to exploited databases are reported in the appendix section.

\subsection{Computation of catchment areas}

The circular catchment areas were computed on QGIS exploiting the native 'Buffer' function for all 7702 AEDs. We decided to implement the traditional areas with $100 \mathrm{~m}$ radius, and to also test areas with $200 \mathrm{~m}$ radius. Two different sets of circular areas of respectively $31^{\prime} 415 \mathrm{~m}^{2}$ and $125^{\prime} 661 \mathrm{~m}^{2}$ were thus computed.

Realistic catchment areas were computed with a dedicated algorithm developed with pgRouting (https://pgrouting.org/) and PostGIS, open source SQL libraries run on PostgreSQL (http://www.postgresql.org) which is available on OSGeo Live (https://live.osgeo.org/en/index.html), the operative system developed by the Open Source Geospatial Foundation (https://www.osgeo.org/). However, realistic catchment areas were not computed for AEDs located more than 200m away (with Euclidian distance) from the nearest mapped street (58 devices were excluded for this reason, that is typical of isolated facilities in natural areas, such as mountain retreats) since in these cases there is no network to build on the catchment areas. Moreover, for statistical purposes one AED only was considered in all the cases where more than one device is mapped with the same coordinates (141 AEDs were excluded for this reason, occurring when more than a device is installed in the same building, usually at different floors). Therefore, realistic catchment areas were computed for a total of 7503 
AEDs (97 \% of the original dataset). The target maximal dimension of the considered walkable paths was set to $100 \mathrm{~m}$ and $200 \mathrm{~m}$, mirroring the dimensioning of circular areas, thus providing two different mapping of realistic catchment areas corresponding to the two measures, as reported in figure 2 . It must be noticed that there is currently no study about the correct dimensioning of the realistic catchment areas, and it is therefore likely that the dimensioning that represents at best the realworld scenario is different from both the considered paths lengths of $100 \mathrm{~m}$ and $200 \mathrm{~m}$. However, since a precise dimensioning is out of the scope of this study, the choice to consider the same measures for the two mapping techniques was assumed as more appropriate for the comparison.

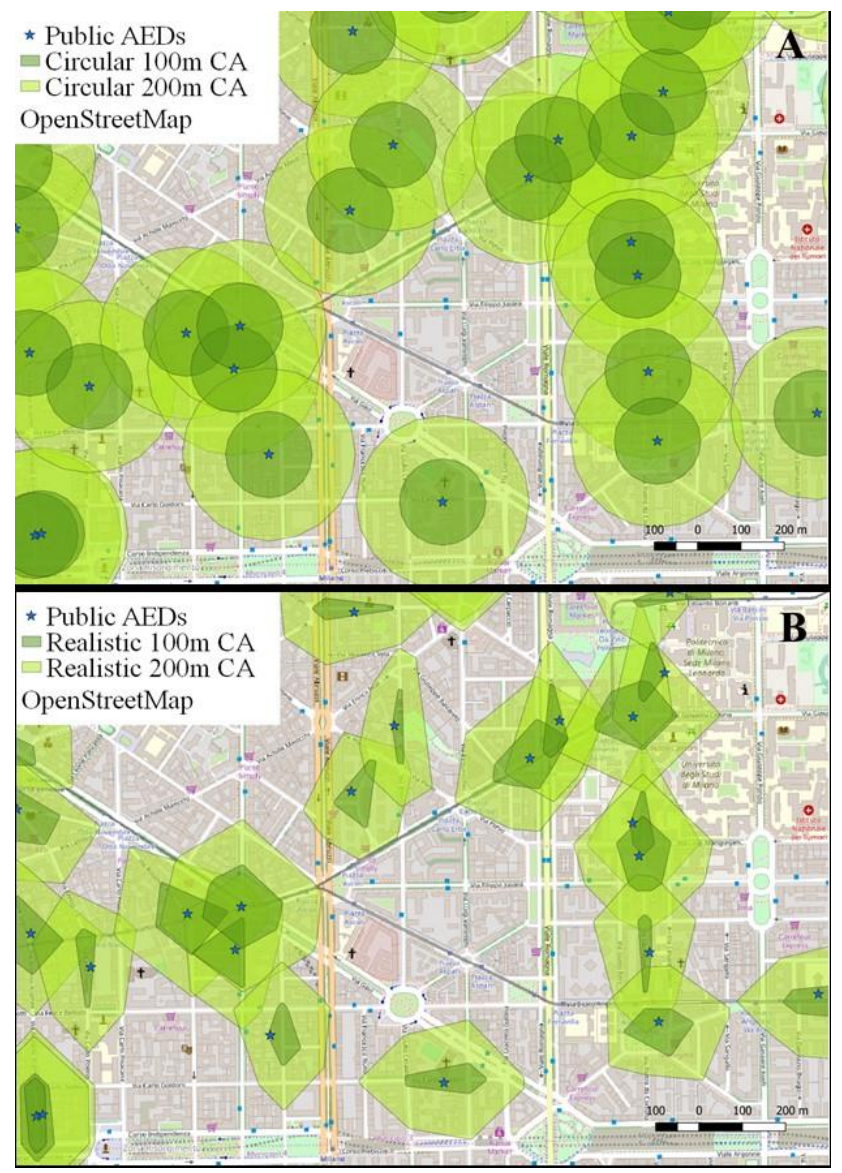

Figure 2. Mapping of circular CAs (panel A) with $100 \mathrm{~m}$ and $200 \mathrm{~m}$ radius and of realistic CAs (panel B) with $100 \mathrm{~m}$ and $200 \mathrm{~m}$ paths for AEDs in a portion of the city of Milan (Lombardy, Italy).

\subsection{Comparison of catchment areas}

By construction, realistic catchment areas computed with $100 \mathrm{~m}$ and $200 \mathrm{~m}$ target dimension resulted significantly different, with an average surface of 6'096 $\mathrm{m}^{2}$ for the first set and 33' $665 \mathrm{~m}^{2}$ for the second (doubling the paths length, the area is over 5 times larger). Therefore, with the same dimensioning measure, the realistic approach provides a much smaller area when compared with circular areas: 6'096 m² vs 31'415 $\mathrm{m}^{2}$ for $100 \mathrm{~m}$ dimensioning (-80.6\%) and $33^{\prime} 665 \mathrm{~m}^{2}$ vs $125^{\prime} 661 \mathrm{~m}^{2}$ with the $200 \mathrm{~m}$ dimensioning $(-73.2 \%)$. This result implies that the two mapping techniques cannot be compared considering the same dimensioning, as the resulting surfaces are too different. However, the realistic areas computed with $200 \mathrm{~m}$ dimensioning resulted, on average, close to the circular areas with $100 \mathrm{~m}$ radius: therefore, in the following analysis the realistic and traditional techniques are compared considering the respective dimensioning of $200 \mathrm{~m}$ paths and $100 \mathrm{~m}$ radius.

The main scope of catchment areas is to evaluate OHCAs coverage, counting the amount of OHCA cases occurred within the catchment areas, which represent the events where a public AED could be effectively used according to spatial distance. Exploiting the QGIS 'Intersection' operation on OHCAs' and catchment areas' layers, it was assessed that if circular- $100 \mathrm{~m}$ areas are considered, the covered OHCAs are $9.43 \%$ of the total (4247 on the total 45043), whereas considering realistic-200m areas the estimated coverage of OHCAs is $15.35 \%$ (6915 on the total 45043). Therefore, although the surface measure is close on average, the choice of the mapping technique has strong implications on the analysis, and the two techniques cannot be considered equivalent, even if different dimensioning is applied as adjustment.

Defining as 'error' the difference between the realistic catchment area and the circular one for each AED, the distribution of this parameter (reported in Figure 3) reveals that realistic mapping generates smaller areas in $51 \%$ of the cases, whereas for the other $49 \%$ the realistic area is larger than the circular one. For 100 of the 7503 considered AEDs, the computation of the realistic catchment area completely failed, resulting in an area equal to 0 and an error of -31 ' $415 \mathrm{~m}^{2}$; moreover, by observing the mapping of realistic catchment areas and manually measuring the computed paths, it resulted evident that there are several undersized areas, that do not properly represent the catchment areas of AEDs. Therefore, we deemed it necessary to inspect these cases in order to identify geographic attributes of the surrounding areas possibly serving as indicators to preventively identify the devices in which the computation of realistic areas would fail.

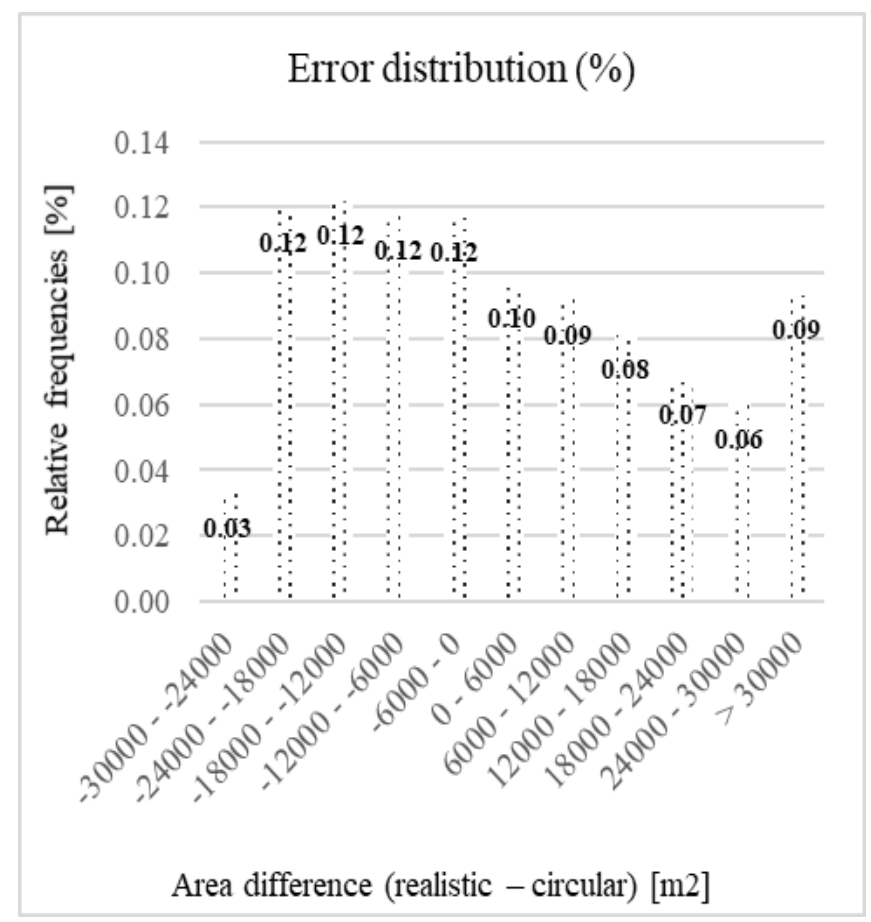

Figure 3. Distribution of the mapping error, defined as the difference for each device between realistic catchment areas and circular ones. 


\subsection{Definition of geographic attributes}

The first considered geographic attribute of AEDs is the Euclidian distance from the device to the nearest street ('dist'), computed from the geographic coordinates of AEDs to points belonging to streets (sampled with $10 \mathrm{~m}$ intervals).

Since all the other geographic attributes characterize the surrounding area, and not the device itself, it was necessary to pre-define the dimension of the surrounding area in which they are computed. This was set within circular areas centred on the device with a radius of $50 \mathrm{~m}, 100 \mathrm{~m}, 150 \mathrm{~m}, 200 \mathrm{~m}$ and $250 \mathrm{~m}$. For all the different area dimensions, we computed:

- Total length of all the roads within the area ('RL', based on OpenStreetMap shapefile);

- Number of roads nodes ('RN', based on OpenStreetMap shapefile);

- Total area of the buildings ('BA', based on OpenStreetMap shapefile);

- A normalized urbanization index ('UR') [0-1], representing the percentage of urbanized surface on the total (based on the DUSAF map);

- A normalized uniformity index ('UI') [0-1], based on the definition of 6 different custom categories of land-use, starting from the DUSAF classification: artificial urbanized, artificial non-urbanized, industrial, transports, agricultural, natural. The index was computed as:

$$
U I=\frac{\sum_{i=1}^{6} \max _{t}-t_{i}}{5}
$$

where $i=$ index for the 6 land-use categories

$\max _{t}=$ percentage of the area covered by the most present land-use category

$t_{i}=$ percentage of the area covered by the $i$-th land-use category.

Accordingly, an area where only one land-use category is present has an UI equal to 1 , whereas an area where all the categories are equally present has an UI equal to 0 .

Considering the 'dist' attribute, which is unique, and 5 other attributes computed on 5 different area dimensioning, the total final number of attributes considered is 26 .

\subsection{Techniques comparison}

In all the performed analyses, outliers were identified and removed by accepting only values that respected the condition: $25^{\text {th }}$ percentile $-(2 * \mathrm{IQR})<$ value $<75^{\text {th }}$ percentile $+(2 * \mathrm{IQR})$, with IQR being the interquartile range $\left(75^{\text {th }}\right.$ percentile $-25^{\text {th }}$ percentile). The multiplier for the IQR was set to 2 instead of the traditional 1.5 as with this value almost $3 \%$ of the records resulted identified as outliers, which was considered an excessive reduction of the sample variability. This method for removal of outliers was chosen and uniformly applied after assessing that no attribute of any dataset resulted to have a normal distribution according to a one-sample KolmogorovSmirnov test with $\mathrm{p}<0.05$.

2.5.1 Attributes correlation with area difference: as a first step, we wanted to verify if the attributes are correlated with the numerical difference between realistic and circular areas, as this kind of information would be useful both in identifying AEDs that are not suitable for realistic mapping and in finding locations where a hypothetical installation of an AED would have a particularly large catchment area. From the considered 7503 starting AEDs, outliers were removed separately on each attribute ( $\min 0, \max 335$ removed records).
After removal of outliers, the linear correlation coefficient between the target variable (realistic $200 \mathrm{~m}$-path area - circular 100m-radius area) and each attribute was computed, considering also exponential and logarithmic transformations of the target variable (for all attributes the significance of the computed correlation coefficients $\mathrm{R}$ was $\mathrm{p}<0.01$ ). Unfortunately, no strong correlation was identified, and only the 'dist' attribute (distance from the device to the nearest street) and the 'RL' attribute (total length of roads within the area) resulted to have a mild correlation, with $\mathrm{R}=-0.61$ for 'dist' and 0.64 for ' $R L$ ' at $50 \mathrm{~m}$ radius, considering the logarithmic transformation of the target variable $(\mathrm{R}=-0.57$ and 0.63 without transformation). Therefore, no more than slightly above the $36 \%$ of the variance in the target variable can be explained with one of these two attributes. Full results for this analysis are reported in table 1 .

\begin{tabular}{|c|c|c|c|c|c|c|}
\hline Attribute & \begin{tabular}{|c}
$\mathbf{r}$ of \\
surr. \\
area \\
{$[\mathrm{m}]$}
\end{tabular} & $\begin{array}{c}\mathbf{N} \\
\text { records } \\
\text { analysed }\end{array}$ & $\begin{array}{c}\mathrm{N} \\
\text { outliers } \\
\text { removed }\end{array}$ & $\begin{array}{c}\mathbf{R} \\
\text { (linear) }\end{array}$ & $\mathbf{R}(\exp )$ & $\mathbf{R}(\log )$ \\
\hline $\begin{array}{l}\text { AED-to- } \\
\text { road dist }\end{array}$ & I & 7307 & 196 & -0.57 & -0.46 & -0.61 \\
\hline \multirow{5}{*}{$\begin{array}{l}\text { Roads tot } \\
\text { length }\end{array}$} & 50 & 7462 & 41 & 0.63 & 0.57 & 0.64 \\
\hline & 100 & 7466 & 37 & 0.60 & 0.50 & 0.61 \\
\hline & 150 & 7485 & 18 & 0.56 & 0.45 & 0.57 \\
\hline & 200 & 7494 & 9 & 0.54 & 0.44 & 0.54 \\
\hline & 250 & 7497 & 6 & 0.52 & 0.40 & 0.51 \\
\hline \multirow{5}{*}{$\begin{array}{l}\text { Roads } \\
\text { nodes }\end{array}$} & 50 & 7168 & 335 & 0.48 & 0.45 & 0.51 \\
\hline & 100 & 7298 & 205 & 0.49 & 0.45 & 0.52 \\
\hline & 150 & 7335 & 168 & 0.44 & 0.40 & 0.47 \\
\hline & 200 & 7381 & 122 & 0.41 & 0.34 & 0.44 \\
\hline & 250 & 7396 & 107 & 0.39 & 0.31 & 0.41 \\
\hline \multirow{5}{*}{$\begin{array}{l}\text { Buildings } \\
\text { tot area }\end{array}$} & 50 & 7452 & 51 & 0.06 & 0.11 & 0.07 \\
\hline & 100 & 7483 & 20 & 0.18 & 0.17 & 0.18 \\
\hline & 150 & 7494 & 9 & 0.24 & 0.17 & 0.22 \\
\hline & 200 & 7493 & 10 & 0.27 & 0.17 & 0.23 \\
\hline & 250 & 7471 & 32 & 0.28 & 0.15 & 0.24 \\
\hline \multirow{5}{*}{$\begin{array}{l}\text { Urban. } \\
\text { level }\end{array}$} & 50 & 7369 & 134 & -0.02 & -0.02 & -0.04 \\
\hline & 100 & 7436 & 67 & 0.14 & 0.12 & 0.12 \\
\hline & 150 & 7469 & 34 & 0.23 & 0.19 & 0.21 \\
\hline & 200 & 7486 & 17 & 0.27 & 0.19 & 0.25 \\
\hline & 250 & 7503 & 0 & 0.30 & 0.21 & 0.26 \\
\hline \multirow{5}{*}{$\begin{array}{l}\text { Uniform. } \\
\text { index }\end{array}$} & 50 & 7503 & 0 & -0.24 & -0.33 & -0.22 \\
\hline & 100 & 7503 & 0 & -0.12 & -0.02 & -0.09 \\
\hline & 150 & 7503 & 0 & -0.02 & 0.05 & 0.00 \\
\hline & 200 & 7503 & 0 & 0.03 & 0.07 & 0.05 \\
\hline & 250 & 7503 & 0 & 0.05 & 0.09 & 0.07 \\
\hline
\end{tabular}

Table 1. Correlation coefficients $\mathrm{R}$ for all the attributes (see text at 2.4 for definition details) with the 'error' (difference between realistic and circular catchment areas), not transformed, exponentially transformed and logarithmically transformed. 
2.5.2 Attributes correlation with failures: A different approach was applied to assess if any of the attributes could provide reliable information for an automatized identification of AEDs for whom a circular catchment area mapping is preferable. Observing the mapping of realistic areas, a threshold value of the area was manually defined to identify failures in realistic mapping, as catchment areas that are smaller than that threshold have to be considered as unrealistic and generated by failures, either for problems in the algorithm or for missing mapped roads on which to compute paths. The threshold was chosen considering intervals of $500 \mathrm{~m}^{2}$, and selecting the first value satisfying the condition of having at least $9 / 10$ failures in the records below the threshold, and at max 1/10 failures above the threshold. The resulting threshold value is $12^{\prime} 500 \mathrm{~m}^{2}$. Accordingly, two different datasets were defined, separating AEDs with realistic catchment areas below and above 12'500 $\mathrm{m}^{2}$ (named in the following 'failures' and 'positives' with respectively 1067 and 6429 records). Outliers were removed from both datasets.

First of all, median $\left(25^{\text {th }}\right.$ percentile, $75^{\text {th }}$ percentile $)$ were computed for all attributes in the two datasets and compared; full results are reported in Table 2. The computed values revealed consistent differences in the two datasets: the 1067 realistic areas considered as failures have a larger distance from the AED to the nearest street, a lower total length of roads in the surroundings (with coherently fewer street nodes), a lower total area of buildings, are less urbanized and the land-use is more uniform.

To assess the significance of these observations, a MannWhitney rank sum test (at 95\% confidence) was chosen, as no attribute resulted to have a normal distribution (one-sample Kolmogorov-Smirnov test with $\mathrm{p}<0.05$ ), and applied separately for each attribute. In order to eliminate any possible influence generated by the different sample size of the two datasets, the Mann-Whitney rank sum test was repeatedly applied between the 'failures' group and 1000 randomly selected subgroups, extracted from the 'positives' group, having the same size of the 'failures' group (1067 records). With this approach, the objective was to verify the percentage of subgroups (extracted from the 'positives' set) that cannot be considered extracted from the same population of the 'failures' group (in these cases, the null hypothesis of the rank sum test is refused at $95 \%$ confidence), separately on the base of each single attribute. The only attribute that generated a negligible percentage of null hypothesis rejections (meaning that its distribution cannot be considered different in the two groups) is the area of the buildings in the 50m-radius surroundings $(8.5 \%$ null hypothesis rejections). The urbanization level in the $50 \mathrm{~m}$ radius and in the $100 \mathrm{~m}$-radius surroundings generated a $99.5 \%$ and $91.8 \%$ of null hypothesis rejections, whereas all the other attributes generated a $100 \%$ null hypothesis rejection (with average $\mathrm{p}$ across all 1000 repetitions significantly lower than 0.01), meaning that in no case their distribution can be considered the same in the two groups, and the differences in medians, $25^{\text {th }}$ percentiles and $75^{\text {th }}$ percentiles are significant and consistent. Full results of the analysis are reported in Table 3.

\begin{tabular}{|c|c|c|c|c|}
\hline Attribute & $\begin{array}{c}r \text { of } \\
\text { surr. } \\
\text { area } \\
{[\mathrm{m}]}\end{array}$ & $\begin{array}{c}\text { Real. Areas } \\
\text { Positives } \\
\text { Median } \\
\left(25^{\text {th }}{\text { perc } 75^{\text {th }} \text { perc }}^{\prime}\right.\end{array}$ & $\begin{array}{c}\text { Real. Areas } \\
\text { Failures } \\
\text { Median } \\
\left(25^{\text {th }} \text { perc } 75^{\text {th }} \text { perc }\right. \\
)\end{array}$ & $\begin{array}{c}\text { Abs. diff. } \\
\text { Median } \\
\left(25^{\text {th }} \text { perc75 } 7^{\text {th }} \text { perc }\right. \\
)\end{array}$ \\
\hline $\begin{array}{l}D-t o- \\
\text { dd dist }\end{array}$ & 1 & $\begin{array}{c}19 \\
(9,34)\end{array}$ & $\begin{array}{c}46 \\
(25,74)\end{array}$ & $\begin{array}{c}-26 \\
(-16,-41)\end{array}$ \\
\hline \multirow{5}{*}{$\begin{array}{l}\text { Roads tot } \\
\text { length }\end{array}$} & 50 & $\begin{array}{c}120 \\
(74,180)\end{array}$ & $\begin{array}{c}7 \\
(0,83)\end{array}$ & $\begin{array}{c}113 \\
(74,97)\end{array}$ \\
\hline & 100 & $\begin{array}{c}478 \\
(331,633)\end{array}$ & $\begin{array}{c}195 \\
(91,360)\end{array}$ & $\begin{array}{c}283 \\
(240,273)\end{array}$ \\
\hline & 150 & $\begin{array}{c}1063 \\
(786,1347)\end{array}$ & $\begin{array}{c}548 \\
(295,888)\end{array}$ & $\begin{array}{c}516 \\
(49,459)\end{array}$ \\
\hline & 200 & $\begin{array}{c}1861 \\
(1394,2310)\end{array}$ & $\begin{array}{c}1072 \\
(661,1654)\end{array}$ & $\begin{array}{c}789 \\
(734,656)\end{array}$ \\
\hline & 250 & $\begin{array}{c}2854 \\
(2180,3513)\end{array}$ & $\begin{array}{c}1791 \\
(1110,2642)\end{array}$ & $\begin{array}{c}1064 \\
(1070,871)\end{array}$ \\
\hline \multirow{5}{*}{$\begin{array}{l}\text { Roads } \\
\text { nodes }\end{array}$} & 50 & $1(0,3)$ & $0(0,1)$ & $1(0,2)$ \\
\hline & 100 & $6(3,11)$ & $1(0,3)$ & $5(3,8)$ \\
\hline & 150 & $14(8,24)$ & $4(1,10)$ & $10(7,14)$ \\
\hline & 200 & $24(14,42)$ & $10(4,21)$ & $14(10,21)$ \\
\hline & 250 & $37(22,63)$ & $18(8,35)$ & $18.5(14,28)$ \\
\hline \multirow{5}{*}{$\begin{array}{l}\text { Buildings } \\
\text { tot area }\end{array}$} & 50 & $\begin{array}{c}1401 \\
(215,2425)\end{array}$ & $\begin{array}{c}1164 \\
(0,2632)\end{array}$ & $\begin{array}{c}237 \\
(215,-207)\end{array}$ \\
\hline & 100 & $\begin{array}{c}4502 \\
(1258,8174)\end{array}$ & $\begin{array}{c}3240 \\
(477,7309)\end{array}$ & $\begin{array}{c}1261 \\
(781,865)\end{array}$ \\
\hline & 150 & $\begin{array}{c}9443 \\
(2838,17338)\end{array}$ & $\begin{array}{c}5893 \\
(1236,14797)\end{array}$ & $\begin{array}{c}3550 \\
(1603,2540)\end{array}$ \\
\hline & 200 & $\begin{array}{c}15788 \\
(4755,29246)\end{array}$ & $\begin{array}{c}10072 \\
(2471,22976)\end{array}$ & $\begin{array}{c}5716 \\
(2284,6270)\end{array}$ \\
\hline & 250 & $\begin{array}{c}23627 \\
(7410,43542)\end{array}$ & $\begin{array}{c}15600 \\
(3673,32441)\end{array}$ & $\begin{array}{c}8027 \\
(3737,11102)\end{array}$ \\
\hline \multirow{5}{*}{$\begin{array}{l}\text { Urban. } \\
\text { level }\end{array}$} & 50 & $\begin{array}{c}0.835 \\
(0.682,0.886)\end{array}$ & $\begin{array}{c}0.877 \\
(0.729,0.886)\end{array}$ & $\begin{array}{c}-0.041 \\
(-0.047,0)\end{array}$ \\
\hline & 100 & $\begin{array}{c}0.739 \\
(0.623,0.849)\end{array}$ & $\begin{array}{c}0.72 \\
(0.554,0.858)\end{array}$ & $\begin{array}{c}0.019 \\
(0.07,-0.009)\end{array}$ \\
\hline & 150 & $\begin{array}{c}0.687 \\
(0.57,0.8)\end{array}$ & $\begin{array}{c}0.639 \\
(0.473,0.779)\end{array}$ & $\begin{array}{c}0.048 \\
(0.097,0.021)\end{array}$ \\
\hline & 200 & $\begin{array}{c}0.654 \\
(0.532,0.767)\end{array}$ & $\begin{array}{c}0.589 \\
(0.422,0.726)\end{array}$ & $\begin{array}{c}0.065 \\
(0.11,0.041)\end{array}$ \\
\hline & 250 & $\begin{array}{c}0.63 \\
(0.5,0.744)\end{array}$ & $\begin{array}{c}0.553 \\
(0.369,0.695)\end{array}$ & $\begin{array}{c}0.077 \\
(0.132,0.049)\end{array}$ \\
\hline \multirow{5}{*}{$\begin{array}{l}\text { Uniform. } \\
\text { index }\end{array}$} & 50 & $\begin{array}{c}0.68 \\
(0.495,0.866)\end{array}$ & $\begin{array}{c}0.868 \\
(0.571,0.984)\end{array}$ & $\begin{array}{c}-0.188 \\
(-0.076,-0.118)\end{array}$ \\
\hline & 100 & $\begin{array}{c}0.503 \\
(0.363,0.705)\end{array}$ & $\begin{array}{c}0.633 \\
(0.424,0.863)\end{array}$ & $\begin{array}{c}-0.13 \\
(-0.06,-0.158)\end{array}$ \\
\hline & 150 & $\begin{array}{c}0.436 \\
(0.316,0.606)\end{array}$ & $\begin{array}{c}0.511 \\
(0.358,0.72)\end{array}$ & $\begin{array}{c}-0.075 \\
(-0.042,-0.114)\end{array}$ \\
\hline & 200 & $\begin{array}{c}0.41 \\
(0.294,0.552)\end{array}$ & $\begin{array}{c}0.456 \\
(0.321,0.646)\end{array}$ & $\begin{array}{c}-0.047 \\
(-0.027,-0.094)\end{array}$ \\
\hline & 250 & $\begin{array}{c}0.39 \\
(0.28,0.52)\end{array}$ & $\begin{array}{c}0.422 \\
(0.298,0.599)\end{array}$ & $\begin{array}{c}-0.032 \\
(-0.018,-0.078)\end{array}$ \\
\hline
\end{tabular}

Table 2. Median, $25^{\text {th }}$ and $75^{\text {th }}$ percentile of all attributes (see text at 2.4 for definition details) for realistic areas, circular areas, and difference between the two datasets. 


\begin{tabular}{|c|c|c|c|}
\hline Attribute & $\begin{array}{c}\mathbf{r} \text { of } \\
\text { surr. } \\
\text { area } \\
{[\mathrm{m}]}\end{array}$ & $\begin{array}{l}\text { \% of Mann-Whitney } \\
\text { U-test null hypothesis } \\
\text { rejections (on } 1000 \\
\text { random subsets) }\end{array}$ & Average p \\
\hline $\begin{array}{l}\text { AED-to-road } \\
\text { dist }\end{array}$ & 1 & 100 & $<0.01$ \\
\hline $\begin{array}{l}\text { Roads tot } \\
\text { length }\end{array}$ & $\begin{array}{l}50 \\
100 \\
150 \\
200 \\
250 \\
\end{array}$ & $\begin{array}{l}100 \\
100 \\
100 \\
100 \\
100\end{array}$ & $\begin{array}{l}<0.01 \\
<0.01 \\
<0.01 \\
<0.01 \\
<0.01\end{array}$ \\
\hline Roads nodes & $\begin{array}{l}50 \\
100 \\
150 \\
200 \\
250\end{array}$ & $\begin{array}{l}100 \\
100 \\
100 \\
100 \\
100\end{array}$ & $\begin{array}{l}<0.01 \\
<0.01 \\
<0.01 \\
<0.01 \\
<0.01\end{array}$ \\
\hline $\begin{array}{l}\text { Buildings tot } \\
\text { area }\end{array}$ & $\begin{array}{l}50 \\
100 \\
150 \\
200 \\
250 \\
\end{array}$ & $\begin{array}{l}8.5 \\
100 \\
100 \\
100 \\
100\end{array}$ & $\begin{array}{l}0.295 \\
<0.01 \\
<0.01 \\
<0.01 \\
<0.01\end{array}$ \\
\hline Urban. level & $\begin{array}{c}50 \\
100 \\
150 \\
200 \\
250\end{array}$ & $\begin{array}{c}99.5 \\
91.8 \\
100 \\
100 \\
100\end{array}$ & $\begin{array}{l}<0.01 \\
0.016 \\
<0.01 \\
<0.01 \\
<0.01\end{array}$ \\
\hline $\begin{array}{l}\text { Uniform. } \\
\text { index }\end{array}$ & $\begin{array}{c}50 \\
100 \\
150 \\
200 \\
250\end{array}$ & $\begin{array}{l}100 \\
100 \\
100 \\
100 \\
100\end{array}$ & $\begin{array}{l}<0.01 \\
<0.01 \\
<0.01 \\
<0.01 \\
<0.01\end{array}$ \\
\hline
\end{tabular}

Table 3. Results of 1000 repeated Mann-Whitney U-tests between 'failures' group and equally sized random subsets of 'positives' group (see text for details).

\section{CONCLUSIONS}

\subsection{Discussion}

Mapping the catchment areas of publicly accessible AEDs (area where the device can potentially be used within the time limit for an effective intervention on OHCA victims) is a critical issue in analysing PAD programs. In this study, two different mapping techniques were compared: a circular buffer centred on the position of the device with fixed radius, and a realistic area based on the walkable paths along streets network within a set maximal distance. The circular areas were computed with radius equal to $100 \mathrm{~m}$ (as traditionally referenced in literature from Aufderheide, 2010) and 200m; the same measures of $100 \mathrm{~m}$ and $200 \mathrm{~m}$ were set as the maximal length of paths for the realistic areas, thus obtaining 4 different shapefiles of catchment areas. The first meaningful result obtained is that the two mapping techniques require different target measures, since considering the same measure for Euclidian and routing distances generates a relative difference in the average of areas between $70 \%$ and $80 \%$. Accordingly, in this study the two techniques were compared considering $100 \mathrm{~m}$ radius for circular areas and $200 \mathrm{~m}$ maximal paths length for realistic areas.

The two different approaches (despite having a close average area after adjusting the target measures) provide significantly different results in terms of OHCAs coverage (number of OHCAs occurring within the catchment areas of public AEDs), due to the strong differences in shape: $9.43 \%$ for circular areas and $15.35 \%$ for realistic areas in our case-study.

Despite realistic areas can be considered more representative of the real-world scenario (and are in general preferable), the observation of the 'error' (difference between realistic and circular areas) revealed that, despite the OHCA coverage is increased when considering realistic areas, there is still a significant amount of mapped realistic areas that underestimate the actual capabilities in area coverage of the devices, and should therefore be considered failures. Unfortunately, among the computed geographical attributes of the area surrounding AEDs (described at 2.4), none resulted strongly linearly correlated with the computed 'error' (or with its exponential and logarithmic transformations).

However, setting a threshold measure of realistic areas for identification of failures (12'500 $\mathrm{m}^{2}$ in our case-study), allowed to assess that almost all the considered attributes have different values distributions in failed and in successful computations. In particular, more reliable results are obtained when analysing an area surrounding the AEDs within a Euclidian distance between 150 and 250 metres. According to the indexes of distribution, it is possible to state that catchment areas of AEDs located in less urbanized areas, with fewer streets and buildings in the surroundings and in areas with more uniform use of the land, are less likely to be effectively represented with the realistic mapping approach. By manually inspecting the map, this condition resulted typical of large and isolated facilities (e.g. sport facilities, airports, warehouses etc.), of areas with specific destination uses all along (e.g. parks, fields etc.) and of natural areas. We can conclude that in all these cases a circular catchment area is preferable, as it can model the coverage of the facilities or of the other walkable land that is outside the mapping of streets, whereas realistic areas should be computed when AEDs are located nearby streets in a densely networked area. According to our results, it is virtually possible to implement an automatized decision-making based on the geographical analysis of the surroundings, exploiting open data only (related to streets, buildings and land-use).

Therefore, our conclusion is that the best current method for mapping of catchment areas of public AEDs is to apply a realistic mapping technique based on the topology of the streets where possible, together with the traditional circular areas in specific locations that can be automatically identified analysing the area surrounding AEDs.

\subsection{Limits and future developments}

The main limit in the current study is related to the accuracy of computation of realistic catchment areas. First of all, there is no golden standard for this computation, and therefore we cannot assess the level of accuracy of our implemented algorithm. In order to reliably identify failures (and to accordingly evaluate the accuracy) it would be necessary to manually classify the whole available dataset distinguishing computation fails from successes. Moreover, the currently implemented method is based on the streets network mapped in OpenStreetMap, and routing paths are strictly developed onto them, meaning that walkable territory outside the streets network (which could still 
be exploited in the real world by people carrying AEDs) is not taken into account. This limit in the available information, although very difficult to overcome on such a large analysis area, implies that realistic catchment areas are strictly bound by roads mapping, that can be considered the main cause of failures in computation in particular in areas where the mapped roads are fewer.

The future developments of this study can be sorted into tackling two main issues:

- Information improvement: exploitation of larger information related to walkable land outside of streets (as previously stated), to additional geographic attributes of areas surrounding AEDs, to larger spatial samples of analysis.

- Development of a classification rule: since all the considered attributes resulted, to some extent, suitable as indicators for identification of AEDs whose catchment area should be mapped as a circular surface, we deem it possible to develop a reliable automatized classification method for identification of these devices. For this purpose, it would be necessary to manually map failures as a golden standard classification, to identify and remove eventual correlations between different attributes (maintaining more informative attributes only and removing those that are internally correlated with them), and to implement a classification algorithm (potentially with a machine learning approach).

\section{REFERENCES}

American Heart Association, 2018: Implementing an AED program DS13398 5/18. https://cpr.heart.org/idc/groups/ahaeccpublic/@wcm/@ecc/documents/downloadable/ucm_501521.pdf

Aufderheide, T., Hazinski, M.F., Nichol, G., Steffens, S.S., Buroker, A., McCune, R., Stapleton, E., Nadkarni, V., Potts, J., Ramirez, R.R., Eigel, B., Epstein, A., Sayre, M., Halperin, H., Cummins, R.O., 2006: Community lay rescuer automated external defibrillation programs: key state legislative components and implementation strategies: a summary of a decade of experience for healthcare providers, policymakers, legislators, employers, and community leaders from the American Heart Association Emergency Cardiovascular Care Committee, Council on Clinical Cardiology, and Office of State Advocacy. Circulation; 113: 1260-1270.

Bonnet, B., Dessavre, D.G., Kraus, K., Ramirez-Marquez, J.E., 2015: Optimal placement of public-access AEDs in urban environments. CAIE; 90:269-280.

Chan, T.C.Y., Li, H., Lebovic, G., Tang, S.K., Chan, J.Y.T., Cheng, H.C.K., Morrison, L.J., Brooks, S.C., 2013: Identifying locations for public access defibrillators using mathematical optimization. Circulation; 127:1801-1809.

Chan, T.C., Demirtas, D., Kwon, R.H., 2017: Optimizing the deployment of public access defibrillators. INFORMS; 62:36173635 .

Deakin, C.D., Shewry, E., Gray, H.H., 2014: Public access defibrillation remains out of reach for most victims of out-ofhospital sudden cardiac arrest. HH Heart; 100:619-623.

Folke, F., Knudsen Lippert, F., Nielsen, S.L., Gislason, G.H., Hansen, M.L., Schramm, T.K., Sorensen, R., Loldrup Fosbol, E., Andresen, S.S., Rasmussen, S., Kober, L., Torp-Pedersen, C., 2009: Location of cardiac arrest in a city centre strategic placement of automated external defibrillators in public locations. Circulation; 120:510-517.

Lin, B.C., Chen, C.W., Chen, C.C., Kuo, C.L., Fan, I.C., Ho, C.K., Liu, I.C., Chan, T.C., 2016: Spatial decision on allocating automated external defibrillators (AED) in communities by multi-criterion two-step floating catchment area (MC2SFCA). Int J Health Geogr; 15:17.

Mauri, R., Burkart, R., Benvenuti, C., Caputo, M.L., Moccetti, T., Del Bufalo, A., Gallino, A., Casso, C., Anselmi, L., Cassina, T., Klersy, C., Auricchio, A., 2016: Better management of outof hospital cardiac arrest increases survival rate and improves neurological outcome in the Swiss Canton Ticino. Europace; 18:398-404.

Renhao, D.M., Eng Hock Ong, M., 2016: Public access defibrillation: improving accessibility and outcomes. $\mathrm{Br}$ Med Bull; 118:27-34.

Ringh, M., Hollenberg, J., Palsgaard-Moeller, T., Svensson, L., Rosenqvist, M., Lippert, F.K., Wissenberg, M., Malta Hansen, C., Claesson, A., Viereck, S., Zijlstra, J.A., Koster, R.W., Herlitz, J., Blom, M.T., Kramer, J., Tan, H.L., Beesems, S.G., Hulleman, M., Olasveengen, T.M., Folke, F., 2018: The challenges and possibilities of public access defibrillation. $J$ Intern Med; 283:238-256.

Roger, V.L., Go, A.S., Lloyd-Jones, D.M., Adams, R.J., Berry, J.D., Brown, T.M., Carnethon, M.R., Dai, S., de Simone, G., Ford, E.S., Fox, C.S., Fullerton, H.J., Gillespie, C., Greenlund, K.J., Hailpern, S.M., Heit, J.A., Ho, P.M., Howard, V.J., Kissela, B.M., Kittner, S.J., Lackland, D.T., Lichtman, J.H., Lisabeth, L.D., Makuc, D.M., Marcus, G.M., Marelli, A., Matchar, D.B., McDermott, M.M., Meigs J.B., Moy, C.S., Mozaffarian, D., Mussolino, M.E., Nichol, G., Paynter, N.P., Rosamond, W.D., Sorlie, P.D., Stafford, R.S., Turan, T.N., Turner, M.B., Wong, N.D., Wylie-Rosett, J., 2011: Heart disease and stroke statistic - 2011 update: a report from the American Heart Association. Circulation. 124:426.

Sasson, C., Rogers, M.A.M., Dahl, J., Kellermann, A.L., 2010: Predictors of survival from out-of-hospital cardiac arrest - a systematic review and meta-analysis. Circ Cardiovasc Qual Outcomes; 3:63-81.

Smith, C.M., Wilson, M.H., Hartley-Sharpe, C., Gwinnutt, C., Dicker, B., Perkins, G.D., 2017: The use of trained volunteers in the response to out-of-hospital cardiac arrest - the GoodSAM experience. Resuscitation; 121:123-126.

Sun, C.L., Demirtas, D., Brooks, S.C., Morrison, L.J., Chan, T.C., 2016: Overcoming spatial and temporal barriers to public access defibrillators via optimization. JACC; 68:836-845.

Tierney, N.J., Mira, A., Reinhold, H.J., Weiser, M., Burkart, R., Benvenuti, C., Auricchio, A., 2018: Novel relocation methods for automatic external defibrillator improve out-of-hospital cardiac arrest coverage under limited resources. Resuscitation; 125:83-89.

Weisfeldt, M.L., Kreber, R.E., McGoldrick, R.P., Moss, A.J., Nichol, G., Ornato, J.P., Palmer, D.G., Reigel, B., Smith, S.C., 1995: Public Access Defibrillation: A Statement for Healthcare Professionals From the American Heart Association Task Force on Automatic External Defibrillation. Circulation; 92:2763. 
Zulli, L., 2016: La Morte Cardiaca Improvvisa - L'arresto Cardiocircolatorio - La Rianimazione Cardiopolmonare. http://internetsfn.asl-rme.it/file_allegati/morte_improvvisa.pdf

\section{APPENDIX}

Links for exploited open data sources:

AEDs in Lombardy region:

https://www.areu.lombardia.it/web/home/mappa-dae-lombardia

OpenStreetMap data:

https://openmaptiles.com/downloads/dataset/osm/europe/italy/n ord-ovest/\#6.18/45.04/9.075

DUSAF for Lombardy region: http://www.geoportale.regione.lombardia.it/metadati?p_p_id=P ublishedMetadata_WAR_geoportalemetadataportlet\&p_p_lifec ycle $=0 \& p \_p \_s t a t e=$ maximized $\&$ p_p_mode $=$ view $\&$ _Published Metadata_WAR_geoportalemetadataportlet_view=editPublishe dMetadata\&_PublishedMetadata_WAR_geoportalemetadatapor tlet_uuid $=\{8$ A509A02-97FD-458A-84D1-

280F81A96640\}\&_PublishedMetadata_WAR_geoportalemetad ataportlet_editType=view\&_PublishedMetadata_WAR_geoport alemetadataportlet_fromAsset=true\&rid=local 